
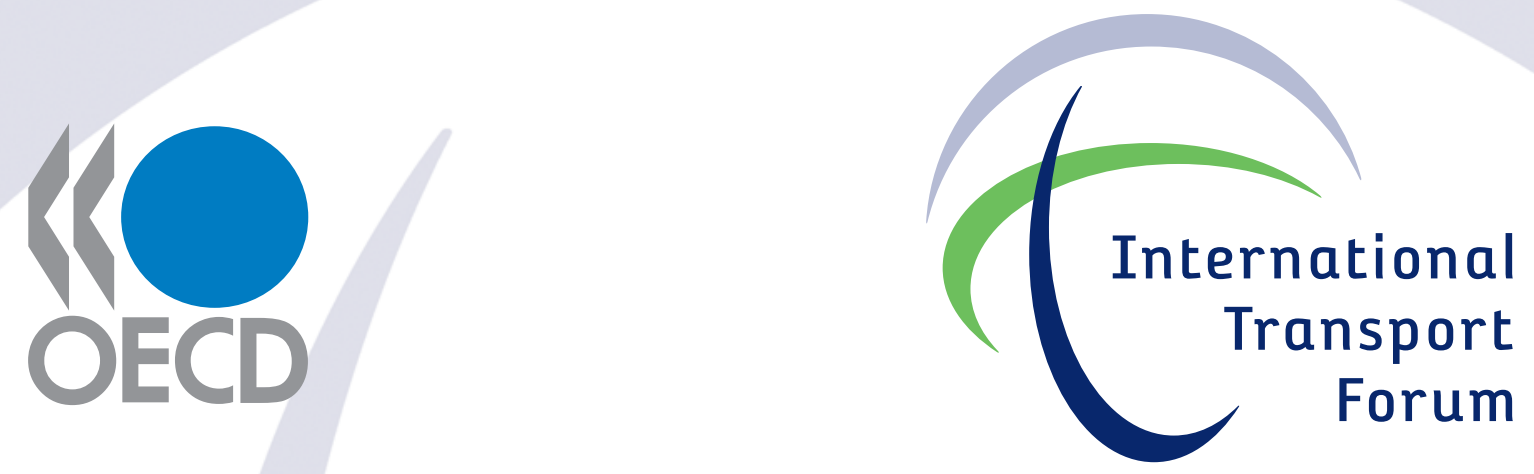

J OINT TRANSPORT RESEARCH CENTRE

$$
\begin{array}{r}
\text { Discussion Paper No. 200q-q } \\
\text { May 200q }
\end{array}
$$

Policy Instruments to Limit Negative Environmental Impacts from Increased International Transport An Economic Perspective

Kurt VAN DENDER and Philippe CRIST J oint Transport Research Centre of the OECD and the International Transport Forum 

Discussion Paper No. 2009-9

\title{
Policy instruments to limit negative environmental impacts from increased
} international transport - An economic perspective

Revised version of a paper prepared for the OECD/ITF Global Forum on Sustainable Development:

"Transport and environment in a globalizing world", Guadalajara, Mexico, 10-12 November 2008

\author{
Kurt VAN DENDER \\ and \\ Philippe CRIST ${ }^{1}$
}

Joint Transport Research Centre of the OECD and the International Transport Forum

May 2009 
The International Transport Forum is an inter-governmental body within the OECD family. The Forum is a global platform for transport policy makers and stakeholders. Its objective is to serve political leaders and a larger public in developing a better understanding of the role of transport in economic growth and the role of transport policy in addressing the social and environmental dimensions of sustainable development. The Forum organises a Conference for Ministers and leading figures from civil society each May in Leipzig, Germany.

The members of the Forum are: Albania, Armenia, Australia, Austria, Azerbaijan, Belarus, Belgium, Bosnia-Herzegovina, Bulgaria, Canada, Croatia, the Czech Republic, Denmark, Estonia, Finland, France, FYROM, Georgia, Germany, Greece, Hungary, Iceland, Ireland, Italy, Japan, Korea, Latvia, Liechtenstein, Lithuania, Luxembourg, Malta, Mexico, Moldova, Montenegro, Netherlands, New Zealand, Norway, Poland, Portugal, Romania, Russia, Serbia, Slovakia, Slovenia, Spain, Sweden, Switzerland, Turkey, Ukraine, the United Kingdom and the United States. The Forum's Secretariat is located in Paris.

\section{Joint Transport Research Centre}

The OECD and the International Transport Forum established a Joint Transport Research Centre (JTRC) in 2004. The Centre conducts co-operative research programmes addressing all modes of transport to support policy making in Member countries and contribute to the Ministerial sessions of the International Transport Forum.

\section{JTRC Discussion Papers}

The JTRC Discussion Paper Series makes economic research commissioned or carried out at the Joint Transport Research Centre available to researchers and practitioners. The aim is to contribute to the understanding of the transport sector and to provide inputs to transport policy design. The Discussion Papers are not edited by the JTRC and they reflect the author's opinions alone. They can be downloaded from:

http://www.internationaltransportforum.org/jtrc/DiscussionPapers/jtrcpapers.html

The International Transport Forum's website is at: http://www.internationaltransportforum.org/

For further information on the Discussion Papers and other JTRC activities, please email: itf.contact@oecd.org 


\section{Introduction}

Transport activities have adverse environmental and health impacts, of which local and regional air pollution, climate change, and noise impacts are the most important. This paper is a non-comprehensive overview of existing and potential policies to deal with these negative impacts, with a focus on "international transport". We define "international transport" as those transport activities that are mainly derived from the globalization of economic activity, not as cross-border transport flows in a more narrow sense. We discuss surface transport, aviation, and maritime transport. The overview is not comprehensive: we focus on climate change, treating other adverse impacts (including aviation noise and local and regional pollution from shipping) more succinctly. This does not reflect a judgment on which impacts are more or less important policy problems, but rather policy interest and the authors' expertise.

Road, maritime and air transport contribute to global emissions of greenhouse gases, and all these modes of transport are generally expected to grow quickly. The transport sector is widely expected to contribute to the abatement of greenhouse gas emissions. We discuss policies to reduce transport's greenhouse gas emissions against the background of a broader discussion of how to deal with the free-rider problem in the global public bad that greenhouse gas emissions are. CO2-abatement in road transport is discussed in some detail, while just a few issues related to maritime transport and aviation are mentioned.

Climate change is a global public bad; abatement of greenhouse gases is a global public good. The absence of a central authority that can decide on, impose, and enforce climate change policies clearly shows in actual policy. The Kyoto-protocol is an attempt to advance with policy in the face of national sovereignty constraints. The approach has met with criticism because of its limited coverage of global emissions, its focus on cap-and-trade systems rather than carbon taxes, its lack of true enforcement mechanisms, and its focus on CO2-abatement rather than stimulating the development and adoption of non-carbonintensive technologies. Alternative approaches seek broader country participation, and sometimes propose enforcement through the World Trade Organisation. Stimulating the use of alternative technologies requires complementary measures to overcome failures in markets for technological development and diffusion.

Road transport is a major source of greenhouse gas emission, and road transport volumes are likely to continue growing. The desirability and the design of abatement policies in road transport poses some difficulties. In the EU and the US, policies are in place that limit energy consumption in transport, even if these policies were introduced for reasons other than climate change. How much further abatement should be demanded from road transport? And which policy instruments ought to be used? We discuss these questions, focussing in particular on possible justifications for fuel economy standards. In particular, we investigate the reasons for the limited power of the market for fuel economy to diffuse more energy-efficient technologies.

Maritime and air transport represent smaller shares of total emissions, but growth has been and may continue to be fast. Both sectors have been less exposed to policies to reduce energy consumption and greenhouse gas emissions than road transport. This suggests that relatively cheap abatement options may be available in those modes, compared to road transport, but fleet turnover in shipping and aviation is slow, and this limits the diffusion of 
available technological improvements. Maritime transport and aviation could be integrated into carbon trading schemes. We discuss some of the research on the effects of including aviation in trading schemes. In general, we find that incentive-based policies are flexible in the sense of allowing low-cost abatement options to be taken up. This is important as technology continues to evolve. Moreover, incentive-based policies stimulate efforts to look for such low-cost options. Standards, however, are useful complements to incentive-based policies in a number of circumstances.

The paper is structured as follows. Section 2 is an overview of current responses to climate change. Section 3 shows how CO2-emissions from transport may evolve, assuming current energy prices do not change strongly. In Sections 4, 5, and 6 we discuss road transport, shipping, and aviation in relation to CO2-emissions. Section 7 provides concluding remarks.

\section{The problem of climate change and current responses}

Climate change is potentially very costly. The consequences of climate change are uncertain (e.g. Stern, 2006) and geographically diverse (e.g. Aldy, 2006). It is very likely that some regions will incur damages, while other regions may experience some benefits. Catastrophic damages are possible as well, and according to some (e.g. Weitzman, 2008) their importance has been understated in much of the economic analysis of climate change up to now.

Climate change is driven by the stock of greenhouse gases, and to a lesser extent by the speed at which the stock grows. Greenhouse gas emissions largely determine the change of the stock, as dissipation is slow. Since the location of emissions is irrelevant, climate change is a global public bad and emission abatement a global public good. As there is no global authority to implement and enforce policy measures, any attempt to design an efficient abatement policy must confront the free rider problem. Free riding means that individual nations or groups of nations benefit from other nations' abatement efforts, and this reduces all nations' incentives to abate.

The challenge of climate change has triggered a wide range of responses. Some countries, e.g. in Scandinavia, have introduced carbon taxes. In many countries, states, cities, companies, and universities have taken a variety of initiatives to reduce emissions. The main multilateral response to climate change is the Kyoto Protocol. This Protocol came into effect in 2005, and requires adhering countries are to reduce emissions to a level defined in terms of the reference year (5.2\% reduction compared to 1990 for industrialized countries as a whole; $8 \%$ for the European Union). In the context of the Protocol, the European Union has introduced the European Trading Scheme (ETS) as a mechanism to reduce the costs of attaining targets by allowing trade in emission permits. The ETS covers about half of total EU emissions, or roughly 8\% of global emissions in 2007. The United States opted out of the Kyoto Protocol, and developing countries are not part of it. The nonparticipation of the US and the fast growth in some of the non-covered countries have substantially reduced the coverage of the Kyoto Protocol: in its original form about $65 \%$ of global emissions in 1990 were covered, whereas actual coverage is now about $32 \%$. If the EU attains the Kyoto targets, global emissions in 2010 are expected to be $26 \%$ higher than in 1990 , compared to a business-as-usual growth of $27.5 \%$. 
The current Kyoto-framework provides only a limited contribution to the reduction of greenhouse gas emissions compared to the business-as-usual scenario. The overall approach behind framework has also been criticized on various grounds. These criticisms imply the Kyoto approach is not the ideal blueprint for future, more comprehensive climate change management institutions. We briefly mention three points of critique.

First, the Kyoto-approach has been described as "narrow and deep". The share of global emissions covered is fairly small, and the covered sources will have to make quite deep and costly cuts to meet targets, while no effort is required from non-covered sources. Several observers, including e.g. Ellerman (2008), favour "broad and shallow" approaches. Broad coverage means that at the very least the US need to be part of an agreement, because of its large share of global emissions and because of the weak incentives for developing nations to join if the US does not participate (e.g. Aldy et al., 2008). In order to increase the chances of cooperation, an enforcement and sanctioning mechanism is required. Stiglitz (2006) argues that a country's failure to charge (somehow) for greenhouse gases in fact constitutes a subsidy to carbon-intensive production, and as such could be sanctioned under the provisions of the World Trade Organisation (WTO), although it is not obvious that the WTO is ready to take on this task. The developing countries are to be included in an agreement as well, although the efforts required from them may initially be weak. The idea is that a broad but shallow system can gradually evolve into a deeper system.

Second, the cap-and-trade approach as adopted in the EU and which will possibly adopted in the US, is thought by many to be (weakly) inferior to a system of carbon taxation. Nordhaus (2007) argues a global harmonized carbon tax outperforms a cap-and-trade system, as the tax avoids the difficult problem of deciding on baseline levels of emissions and creates no rents and consequently no costly rent-seeking (see also Stiglitz, 2006). A tax is also better suited to deal with uncertainty over abatement costs, given that marginal benefits of abatement are highly elastic (as abatement is defined over emissions while impacts depend on the stock of greenhouse gases). Furthermore, taxes generate valuable public revenue, which grandfathered permits don't. Aldy et al. (2008) point out that cap-andtrade systems can be modified to improve their performance relative to taxes (by auctioning permits, by introducing safety-valves and allowing intertemporal reallocation of permits, etc.), so that the practical difference between "good" cap-and-trade systems and taxation approaches is ultimately small.

The level of the tax or the price of a permit can be determined by referring to marginal damage estimates or by referring to a target for atmospheric concentrations of CO2. According to Aldy et al., 2008, with marginal damages of USD 10 per ton of CO2 (USD 36.7 per ton of carbon), the price of gasoline in the US would increase by USD 0.09 per gallon (USD 0.023 per litre). The marginal damage cost estimate in the Stern report is about USD 85 per ton of $\mathrm{CO} 2$, so the price changes need to be factored up by 8.5 if these higher estimates are taken to be relevant. An atmospheric concentration target of 450 parts per million is thought to correspond to a global temperature increase of about $2^{\circ} \mathrm{C}$, and requires carbon prices similar to those of the Stern report. A price of USD 10 per ton of CO2 is taken to be similar to concentrations of $550-650$ parts per million $\left(3-3.6^{\circ} \mathrm{C}\right.$ temperature increase).

If the price of carbon is to be determined in a top-down approach, a global administering and sanctioning mechanism is called for. Aldy et al. (2008) suggest the WTO as the most straightforward choice for housing such an organisation, although it is not obvious that the WTO is ready to take up such a role. One of the main tasks of the administration would be to monitor "fiscal cushioning", i.e. countries efforts to reduce the effective carbon tax by 
tweaking other attributes of national taxation schemes. The problem of calculating "effective carbon taxes" would be highly relevant for the transport sector (see below). It is far from obvious, however, that progress with multilateral coordination of greenhouse gas abatement efforts will be made through a multilateral top-down approach. A different scenario is that the US will introduce its own cap-and-trade system (see Meckling, 2008, for an assessment of the changing position of corporate lobbies), while the EU continues with the ETS and develops it to more stringent system where caps are stricter and permits are auctioned. Separate trading schemes may later be connected to exploit further gains from trade.

International aviation and maritime transport are not covered by the Kyoto Protocol. Instead, the Protocol recommends that ICAO and IMO develop policies for these sectors. However, while the Kyoto approach is one of common but differentiated responsibilities (implying relatively strong efforts from richer countries), ICAO and IMO have no such tradition of differentiation. This slows down progress on policy development within these organizations, leading other bodies (notably the EU) to implement (in the case of aviation) or threathen to implement (in the case of shipping) measures for international aviation and shipping. A gradual approach, with relatively limited efforts from non-Annex 1 countries in early stages, may be the most productive way forward here as well. Kageson (2009) discusses what such a gradual approach could look like.

Ellerman (2008) emphasizes the importance of club benefits for a cap-and-trade system to be feasible: the European Commission managed to get new Member States to sign on to the ETS because the cost of doing so was diluted in the larger package of costs and mainly benefits of joining the European Union. Conceivably, the US - with a stronger federal structure than the EU - could make continued access to club benefits for US States conditional on joining a US carbon trading scheme. On a global scale, the club benefits relate mainly to those offered by the WTO (Stiglitz, 2006).

With a bottom-up approach, there are likely to be differences between the emerging trading schemes. For example, the ETS does not include transport and is not likely to include road transport any time soon. A US system, however, may very well include transport from the start (Ellerman et al., 2006). At any rate, the relation between prevailing transport policies and carbon pricing schemes needs careful consideration; we discuss this in Section 4.

A third criticism on the Kyoto-type approach is that its focus on abatement of greenhouse gases, in particular CO2, is too narrow. For example, Barrett (2007) argues for a broader approach that includes adaptation, incentives for technological development, and the development and sharing of knowledge. Aldy et al. (2008) and Newell (2008) concur that the social returns to technological innovation and diffusion are larger than the private returns, so there is a case for policy intervention. One policy approach would be to increase carbon prices over marginal damages, but this instrument may be poorly targeted. The economic understanding of which policies work best is limited, especially where transformative technological change is concerned. It is sometimes argued that financial incentives are insufficiently powerful to ensure the adoption of alternative technologies, so that standards may become desirable. This may be the case, for example, when end-users valuation of improved energy-efficiency is low (too low?), as is often argued to be the case in private vehicle markets. We discuss the issue further in the next section.

Summing up, it seems likely that progress with broad climate change management systems will take place through a bottom-up process, with the gradual emergence of regional systems adapted to regional circumstances. Different conditions may lead to different 
treatment of transport sectors in the regional systems. A potential problem with this process is the limited incentive for nations with low willingness to pay for abatement, to join. Technological change is key for handling climate change. This holds for transport at least as much as for other sectors, and policy approaches that focus on reducing transport's carbon intensity deserve close attention. The challenge for the sector is immense, as will be clear from the next section.

\section{Transport and CO2-emissions: where demand would like to go}

The ITF produced a first transport outlook in 2008. It used the IEA/ETP's MoMo model to construct projections of CO2-emissions, focusing on road transport under alternative assumptions on the evolution of demand. The ITF business as usual scenario (BAU) is the same as the IEA/ETP 2008 Reference Scenario. Figure 1 displays a key model output: tankto-wheel $\mathrm{CO}_{2}$-emissions from vehicles, in Million tons of $\mathrm{CO}_{2}$-equivalent, from 2000 through $2050 .^{2}$ The emission paths for the transport modes contained in the MoMo-model are shown. Section 4 of this paper emphasizes emissions from light-duty vehicle (LDV) emissions. This is justified given the large share of these emission in the total, but it is clear that emissions from air transport are expected to grow more rapidly than those from light-duty vehicles; aviation emissions policy is briefly discussed in Section 6. Emissions from other modes, including shipping, are expected to grow as well. In addition, it is likely that the BAU underestimates emissions from shipping (see Section 5). Table 1 provides detail on the model composition of global vehicle emissions.

Emissions from light-duty vehicles grow strongly over the model horizon: emissions in 2050 are nearly $91 \%$ higher than in 2000. Growth is moderate between 2010 and 2030 but accelerates after 2030. The drivers of light-duty vehicle emissions are the following: the size of the car stock, the intensity with which vehicles are used, and the carbon-intensity of the energy sources used. The growth of the total stock is the key driver of increased emission levels, with global ownership levels rising threefold from 669.3 million vehicles in 2000 to 2029.9 million vehicles in $2050 .{ }^{3}$ This expansion in turn is the consequence of increased ownership rates that occur mainly in emerging economies. The technological composition of the stock changes, as the share of conventional gasoline vehicles declines from $87 \%$ to $68 \%$ while that of diesel vehicles increases from $12 \%$ to $26 \%$ and that of hybrid gasoline vehicles

2 The projections do not account for the current economic and financial crisis. If the current shock is transient and the world economy returns to the same growth mechanisms as before, the attainment of the transport demand and emission levels as sketched will be delayed by five years or so (well within the margin of error of the model). But if there are profound changes to the functioning of the economy, either because of policy or because of adaptation to economic realities, more modest growth paths can be expected. In either case, the climate change problem still looms large.

3 The BAU assumes a decline of the intensity of vehicle use in developed economies. The average light-duty vehicle is driven about $18,000 \mathrm{~km}$ per year in OECD North America in 2000, declining to about 16,000 km per year in 2050. In OECD Europe, average use declines from $13,000 \mathrm{~km}$ to $11,000 \mathrm{~km}$ per year over the same period. The underlying assumption is that an expansion of the stock in these economies reduces usage of each individual vehicle. In non-OECD economies, the average distance driven remains more or less constant throughout the period. 
rises from $0.1 \%$ to $4 \%$. Hence, there is a shift to less carbon-intensive technologies, but not a major switch to truly low carbon technologies.

The emission profile in Figure 1 directly depends on assumptions concerning the size of the vehicle stock, vehicle use, and vehicle technology. It is useful to note that the BAU scenario presented is an outline of "where demand would like to go". By this we mean that the supply of energy is assumed to be fairly elastic, so that strong growth in demand does not lead to strong increases in the price of transport energy. This is not a straightforward assumption, given for example the growing concern about supply side constraints and consequent high prices in current oil markets, which recently have been shown to affect demand. In addition, the development of GDP drives demand, and the current crisis may lead one to think the BAU assumptions are optimistic (see footnote 2).

Figure 1. World Tank to Wheel $\mathrm{CO}_{2}$ Emissions, $\mathrm{BAU}, 2000-2050$, Mt of $\mathrm{CO}_{2}$-equivalent

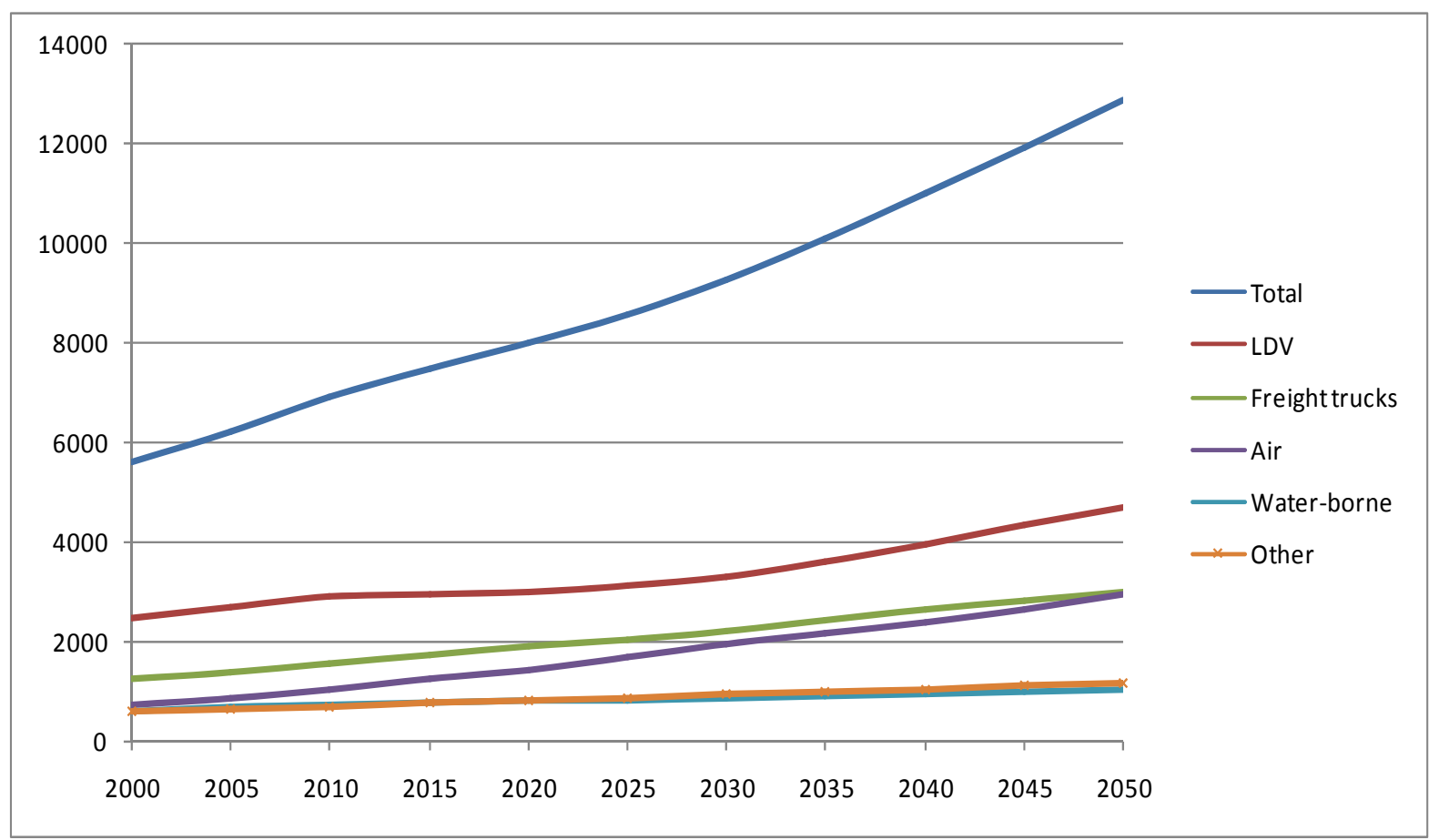

Source: ITF calculations using the IEA MoMo Model Version 2008. 
Table 1. Modal shares in World Vehicle $\mathrm{CO}_{2}$-emission, BAU, 2000-2050, \%

\begin{tabular}{|c|c|c|c|c|c|c|c|c|c|c|c|}
\hline \multicolumn{12}{|l|}{ BAU } \\
\hline & 2000 & 2005 & 2010 & 2015 & 2020 & 2025 & 2030 & 2035 & 2040 & 2045 & 2050 \\
\hline Freight + Passenger rai & 2.1 & 2.2 & 2.3 & 2.5 & 2.7 & 2.8 & 2.9 & 2.9 & 2.9 & 2.9 & 3.0 \\
\hline Buses & 6.8 & 6.3 & 5.7 & 5.4 & 5.2 & 4.9 & 4.6 & 4.3 & 4.1 & 3.8 & 3.6 \\
\hline Air & 12.9 & 13.5 & 14.8 & 16.8 & 18.1 & 19.5 & 21.1 & 21.5 & 21.8 & 22.3 & 23.0 \\
\hline Freight trucks & 22.4 & 22.2 & 22.8 & 23.4 & 23.9 & 24.0 & 23.7 & 24.1 & 24.1 & 23.8 & 23.4 \\
\hline LDVs & 43.8 & 43.3 & 41.9 & 39.5 & 37.6 & 36.4 & 35.6 & 35.6 & 35.9 & 36.4 & 36.5 \\
\hline 2-3 wheelers & 1.6 & 1.8 & 2.0 & 2.2 & 2.5 & 2.6 & 2.6 & 2.6 & 2.6 & 2.5 & 2.4 \\
\hline Water-borne & 10.4 & 10.8 & 10.3 & 10.2 & 10.0 & 9.8 & 9.5 & 9.0 & 8.6 & 8.3 & 8.0 \\
\hline Total & 100 & 100 & 100 & 100 & 100 & 100 & 100 & 100 & 100 & 100 & 100 \\
\hline
\end{tabular}

Source: ITF calculations using the IEA MoMo Model Version 2008.

\section{Road transport ${ }^{4}$}

\section{Abatement costs in transport and in other sectors}

In deciding how to achieve an abatement target for greenhouse gas emissions, however determined, it makes sense to start with the cheapest abatement opportunities and select increasingly expensive options until the target is reached. Applied general equilibrium models of various degree of detail that have been used to obtain an economy-wide view of greenhouse gas abatement opportunies, their costs and their effects on emissions (e.g. Proost, 2008 and Abrell, 2007), often find that the effort in the transport sector is small compared to its share in total emissions.

The rationale for the limited effort in transport is that abating in transport is expensive, with high costs for technology as well as for behavioral change. There are several reasons why abatement technology is relatively expensive in transport. First, there are few cheap lowcarbon substitutes for conventional engine technology. Second, transport fuels have been relatively expensive (compared to other sectors) in many parts of the world, mainly because of relatively high taxes. These high prices have induced the market to take up cheap abatement options already, making further reductions expensive. Third, transport fuels are less carbon-intensive than some other fuels, so that carbon taxes would have smaller effects on energy prices in transport than in other sectors. For example, introducing a tax of USD 50 per ton of carbon in the US would increase the price of coal by about $140 \%$, while the price of gasoline would rise by $6 \%$ (Parry, 2007), implying more limited incentives for abatement in transport.

While the arguments explaining relatively high abatement costs in transport are sound, they are challenged on various grounds. One objection is that the assumptions on costs of alternative technology embedded in the general equilibrium models are too high, as no account is taken of declining costs when production levels rise. Experience suggests that costs indeed do generally decline. Whether this will also hold for technologies such as batteries etc., is plausible but uncertain. Another objection is that the arguments explaining higher costs in transport are partly empirical, but also are partly based on economic inference: further abatement in transport must be relatively costly because energy was relatively expensive in the past and alternatives have not yet been adopted. This inference

$4 \quad$ A more extensive version of the arguments developed in this section can be found in Van Dender K., 2009, Energy policy in transport and transport policy, forthcoming in Energy Policy. 
relies on the assumption that transport markets work very well, in the sense that all surplusimproving technological potential is realized. Abandoning this assumption modifies results, as is discussed next for the market for vehicle fuel economy.

\section{A case for fuel economy standards?}

It is sometimes argued that improving vehicle fuel economy for passenger vehicles is a no regret abatement option, because the discounted savings on fuel expenditures outweigh the costs when using standard private discount rates. However, there is evidence that consumers use very high discount rates when deciding on fuel economy, resulting in limited investment in it. For example, Turrentine and Kurani (2007) find that consumers implicitly require payback periods of 3 years or so for investments in better fuel economy, indicating that implicit discount rates are high. Work done for the Impact Assessment of the EC's proposed fuel economy regulation (EU, 2007) finds that the discount rate that equalizes increased vehicle costs and reduced fuel expenditures is around $20 \%$, much higher than standard values for private discount rates. ${ }^{5}$, While not definitive evidence, this might be interpreted as an indication that there are market imperfections beyond consumer "myopia" that justify a policy intervention. ${ }^{6}$

Why would high discount rates be used when deciding on fuel economy? One argument is that consumers pay little attention to fuel economy, because they care more about other attributes and the share of fuel costs (and therefore a fortiori the size of savings from better fuel economy) in total purchase and usage costs is small. Given that processing information on how fuel economy translates into probable savings on fuel expenditures takes costly effort, consumers may decide a detailed calculation is not worthwhile. From a policy perspective, this problem may be overcome by providing better information on potential savings from purchasing better fuel economy. From an analytical perspective, the argument says that consumers make inaccurate decisions on fuel economy, but not that they systematically invest too little.

Recently, Greene et al. (2008) suggested a framework that does imply systematic undervaluation of fuel economy compared to the textbook model of an expected-utilitymaxizing consumer. They show that when consumers are loss averse ${ }^{7}$ and uncertain on factors that determine optimal fuel economy, they will invest less in fuel economy than consumers that maximize expected utility ${ }^{8}$. The uncertain factors that affect fuel economy choices are the gap between real and labelled fuel economy, the lifetime of the car, the amount of driving, and fuel prices, among others. Among those factors, uncertainty on realized fuel economy is the main driver of low investment, according to a calibrated

\footnotetext{
$5 \quad$ Number taken from a March 12, 2008 email exchange with Richard Smokers, with permission.

6 If policy steers the use of technology towards fuel economy, the cost needs to be calculated as the difference in surplus produced by the use of technology best liked by consumers, and the surplus from using technology to improve fuel economy.

Loss aversion means that consumers evaluate outcomes in terms of changes from a reference state of wealth, and that losses are valued more than equivalent gains (to a larger extent than can be explained by declining marginal utility).

It was noted in JTRC (2008) that, contrary to expectations, fuel economy decisions for company car fleets and for freight trucks are prone to similar imperfections as those for privately owned light-duty vehicles. Loss aversion may help explain this phenomenon as well.
} 
numerical exercise. The numerical example also suggests the impact of loss aversion is large, as the expected saving from a fuel economy improvement of USD 405 for an expected utility maximizer is equivalent to a loss of USD 32 in the case of loss aversion.

According to Greene et al. (2008), low willingness to pay for fuel economy by consumers translates into strategies on manufacturers' part that steer vehicle design towards more marketable attributes, like power and comfort. With such a supply response, available fuel economy turns out lower than in a world where consumers are not prone to loss aversion. A manufacturer will be disinclined to use technology to provide better fuel economy if there is large uncertainty on whether consumers will want to buy it and on how competitors will respond to the same problem. A fuel economy standard can correct this problem, as it provides clarity on what performance level needs to be reached, by a manufacturer and by its competitors.

The loss aversion argument is compelling in the sense that it provides a theoretical argument for consumers' low willingness to pay for fuel economy improvements, argues convincingly that this demand curve is what producers take into account when deciding on what fuel economy levels to provide, and that a standard is a good way of making sure manufacturers deviate from this demand curve and provide better fuel economy. The case for a standard is particularly strong when fuel taxes are low and incomes high, as both factors exacerbate the gap between consumers' aspirations, which drive supply decisions, and policy targets for fuel economy. This gap is wide in the US, but it also prevails in Europe. For example, it is reasonable to think that the failure of the voluntary agreement in the EU to reduce CO2-emissions was partly caused by the lack of policy initiative to support the agreement during a period of strong economic growth and declining real fuel prices, at least in the early years.

However, it is not clear that loss aversion provides a basis for policy intervention, unless one explicitly takes the hypothetical market outcome that would be obtained in the absence of loss aversion as the norm, instead of letting consumers optimize according to their loss averse preferences. Doing so might open up discussions on a wide array of interventions, as loss aversion is not unique to this particular market.

While it is not clear that loss aversion justifies a correction of a failure in the market for fuel economy, a different approach is to focus on cost-effectiveness and ask whether loss aversion and uncertainty could affect the choice between quantity-based regulation and prices to attain an abatement target, however defined. Loss aversion and uncertainty on the part of consumers lead to uncertainty for producers on how much to invest in fuel economy, and this results in fuel economy levels that reflect high implicit discount rates. Higher fuel prices increase what consumers want to pay for fuel economy but does not affect their treatment of uncertainty, so does not alleviate producer uncertainty either. Consequently, government can not be not sure how effective a tax-based approach will be in triggering investments. If government cares about such investments, for example because it believes this makes policy less prone to reversibility by future policy-makers (Glazer and Lave, 1996; Barrett, 2005) or because it wishes to stimulate the diffusion of new technologies (Aldy et al., 2008), then it may favor a quantity-based approach over a price-based one, precisely because the quantity-approach reduces flexibility. In this approach, where the government 
has a preference on how fuel consumption in transport is reduced, the choice for a standard for fuel economy may be justified. ${ }^{9}$

Given these arguments for fuel economy standards, it appears that existing and proposed standards require bigger improvements in fuel economy than can be justified by market imperfections. Indeed, the stringency of standards seems consistent with a policy approach that either starts from the assumption that technology to improve fuel economy is very cheap, or that implicitly attaches a very high value to reducing greenhouse gas emissions and improving energy security, but which lacks a clear view on what costs are imposed on consumers. We suggested possible motivations for ambitious abatement targets above, and Barrett (2005) notes that policies to stimulate technology take-up may be required. Nevertheless, with the current evidence the basic message from the analyses of the general equilibrium type remains valid: abatement costs in transport appear to be relatively high.

Despite their weak connection to market failures, prevailing and proposed fuel economy regulations are insufficiently ambitious to attain a stabilization of global CO2-emission from road transport. According to JTRC (2008b), stabilization through 2050 at 2010 levels requires attainment of a fleet-average fuel economy of 3.51/100km (approximately 67 miles per gallon) in 2050. Figure 2 shows that current regulations are far from such levels.

$9 \quad$ The government may also prefer using a standard because it cares strongly about reaching the abatement target, perhaps out of a sense of urgency, and less about how much it will cost to get there. This argument has no direct relation with the issue of loss aversion. 
Figure 2. Comparison of fuel economy and GHG standards, normalized by CAFE-converted MPG

\section{Actual and Projected Fuel Economy for New Passenger Vehicles by Country/F}

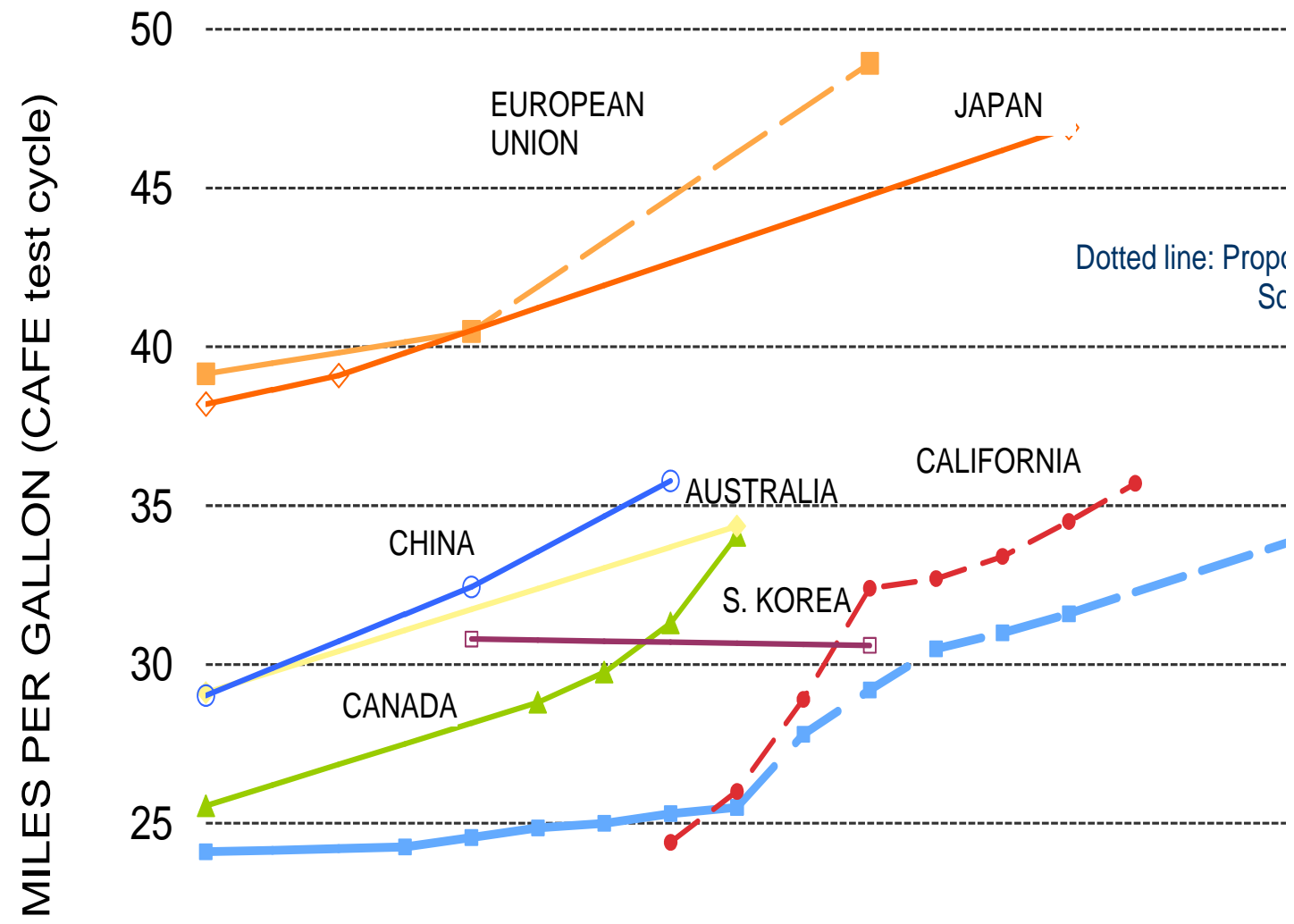

\section{Climate change and other external costs of transport}

We briefly discuss the relative importance of the main external costs of transport by comparing estimates of their current order of magnitude, where we look at averages over a large class of users. When considering energy and transport policies, this comparison provides some indication on how policy priorities could be defined. Table 1, taken from Small and Van Dender (2007), collects estimates of the main marginal external costs of road passenger transport, and classifies them according to whether they depend mainly on fuel consumption (climate change and oil dependency) or on vehicle-miles travelled. For comparison, the fuel-related external costs are converted to a marginal cost per vehicle-mile, using the fleet average fuel efficiency for passenger vehicles (i.e. $22.9 \mathrm{mi} / \mathrm{gal}$ for the US in 2005). 
Table 2. Marginal external costs from automobiles, US cents/mile, 2005 prices

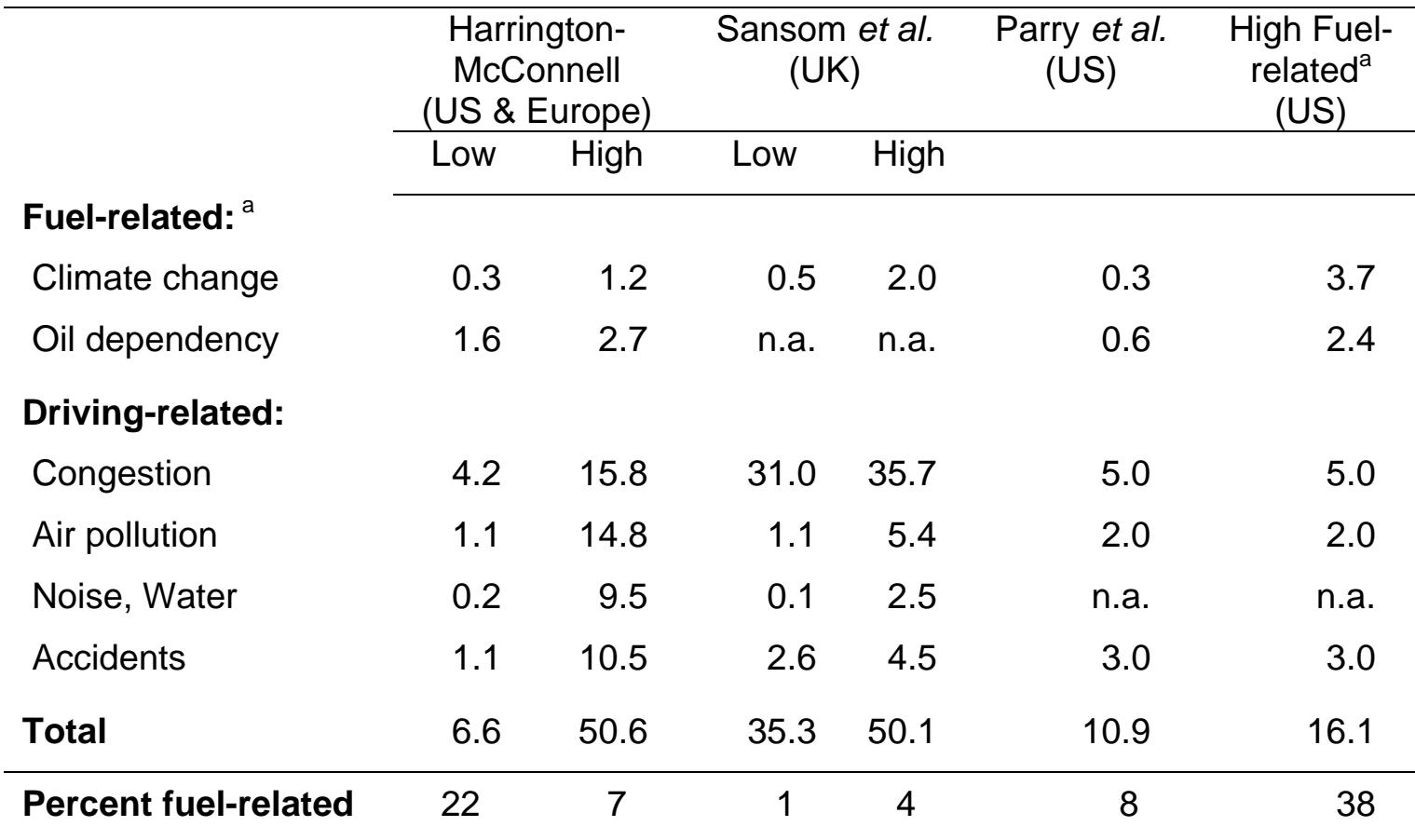

Sources: Harrington and McConnell (2003), Table 2; Sansom et al. (2001); Parry, Walls and Harrington (2007), Table 2. "High Fuel-related".: same as Parry et al. except for climate change (USD 0.76/gal, from Stern 2005) and oil dependency (USD 0.55/gal, from the high end of range in Leiby (2007), Table 1.

Notes: All numbers converted to 2005 US price levels. n.a. means not estimated, in some cases due to an explicit argument that the quantity is small. Fuel-related costs are converted from per gallon to per mile using prevailing average fuel efficiency.

The three studies listed in Table 2 (excluding the last column) are unanimous in finding that congestion involves larger external costs than fuel-related externalities, and except for the "low" Harrington-McConnell values, the same is true of air pollution and accidents. In nearly all cases, congestion alone is found to outweigh the fuel-related externalities by a large margin. If we use the higher fuel-related figures in the last column of the table, the picture changes somewhat, although even then fuel-related externalities do not dominate other externalities. However, the validity of the averages in the table as guides for policy can be questioned. In the case of climate change, the main problem is the enormous uncertainty, as mentioned before and emphasized by Weitzman (2007). With respect to energy security, the argumentation underlying the numbers is not entirely convincing; we refer to Small and Van Dender (2007) for a discussion.

The best policy responses to fuel-related and mileage-related externalities are quite different. Raising the price of fuel induces a mileage reduction but also, and to an increasing extent, an increase in fuel efficiency (Small and Van Dender, 2007). This means that a fuel tax is not a very effective instrument to address mileage-related externalities, and a distancebased tax would perform much better (cf. Parry and Small, 2005, for a numerical illustration). However, using a distance-related tax to address a fuel-related externality such as global warming would fail to elicit one of the most important responses needed, which is an increase in fuel efficiency of vehicles. In addition, although better than a fuel tax, a mileage 
tax is not ideal for handling congestion, which varies strongly over time an place. There is strong evidence that the response to imposing targeted congestion charges (i.e., ones that vary by time and place) would involve a lot of shifting of trips across time periods, modes, and routes, and much less overall reduction of trips; thus the most efficient policies would aim at shifting trips in this manner rather than simply reducing all trips.

The climate-change cost calculated by Parry et al. (2007), shown in the next to last column of Table 2, is based on a damage estimate of USD 25 per tonne carbon, i.e. USD 25/tC, at 2005 prices, a figure found in several reviews (e.g. Tol, 2005) but lower than those in Stern (2006). The marginal cost of damage from carbon emissions is, however, highly uncertain.

Weitzman (2007) provides an insightful discussion of a rationale for using higher marginal damage estimates than those implicit in table 1 .. In his view, the most important issue is uncertainty about the prospects and consequences of unlikely but extremely damaging results of climate change. The standard cost-benefit framework has no explicit way of dealing with such events, so may instead implicitly use the discount rate to do so. Weitzman (2008) is an attempt to allow an explicit treatment of extreme events (extreme in their probability and in their consequences). His proposed a framework to deal with structural uncertainty finds much stronger support for policies to mitigate quickly than in the traditional model.

For the transport sector, this means that policy design is more conveniently thought of in terms of cost-effectiveness than in terms of market imperfections within the transport sector. With ambitious abatement targets, decarbonisation through alternative technologies should be part of a long run strategy. Research and development will only be realized if there is a strong policy commitment to climate change targets. Public funding for research is justified to the extent that the social returns exceed the private returns, and to the extent that policy commitment remains uncertain (Newell, 2008).

We believe that damage estimates of the orders of magnitude shown in Table 2, excluding the right-most column, are the best guides to a transport policy that deals with driving-related externalities. For an energy policy to deal with climate change, the large uncertainty on impacts justifies measures to reduce carbon emissions, arguably also in transport. A fuel economy standard can be seen as one element of such a strategy, as it helps control the expected growth of emissions. More ambitious abatement targets require large scale deployment of alternative technology. Measures to stimulate the development and use of alternative technology may be justified, but we don't see a strong case for strong policy-directed changes in transport activity on climate change grounds. An ideal approach to controlling energy use is not likely to reduce motor vehicle travel very much, but instead will accomplish most of its results through technological changes specifically targeted to energy savings, mostly through the use of more fuel-efficient vehicles and through alternative fuels. By choosing technological solutions when permitted, consumers will avoid more thoroughgoing behavioural changes such as changes in travel mode, trip patterns, and home and work location, which evidently are more costly for them. Measures to address congestion may induce changes in patterns of travel demand that imply reductions of greenhouse gas emission, but not enough to meet ambitious abatement targets. 


\section{Road transport and cap-and-trade systems}

Road transport in many countries is subject policies that reduce fuel consumption and greenhouse gas emissions below no-intervention levels. The EU, for example, has high fuel taxes and now has a fuel economy standard. The US has lower fuel taxes but the CAFE standard has been binding for decades. How should such pre-existing policies be accounted for in the design of a broader cap-and-trade system?

As a starting point, one can calculate the price of carbon that is implied by current policies in road transport. For example, Ellerman et al. (2006) find that the CAFE standard in the US corresponds to a price of USD 90 - USD 110 per ton of carbon. Fuel taxes in the EU imply considerably higher carbon prices. These carbon prices are higher than what is expected to result in cap-and-trade regimes, and consequently there are efficiency gains from including road transport in a cap-and-trade scheme (which aims to minimize abatement costs by equalizing marginal costs across sectors). The EU has chosen not to include road transport in the ETS, however. Ellerman et al. (2006) propose inclusion of road transport in any future carbon trading scheme, because of the potential efficiency gains of doing so.

A potential problem with this calculation is that prevailing policies do not address climate change externalities alone. The CAFE program was introduced to deal with energy security, and climate change justifications emerged only later. The level of fuel taxes in the EU is determined by many factors, first and foremost as a relatively efficient way of raising revenues for general public expenditure. Fuel taxes in the US are lower and are related to road infrastructure expenditures (although less and less so). Nevertheless a comparison of energy security costs and climate change costs might suggest current US fuel taxes are sufficiently high to cover these externalities, if moderate values are used for carbon damage. In order to decide how a tax or a standard ought to be changed if it is to address climate change (where it did not before), it needs to be made clear which external costs a fuel tax (or a standard) is supposed to address and to which extent it is a revenue raising instrument. Parry and Small (2005) assume that fuel taxes are a second-best instrument to address local and global pollution as well as average marginal external costs of congestion, and find that current US taxes should be roughly doubled while UK taxes should be halved if they are to be set at the second-best level. The congestion costs are the main component of the tax. If congestion were to be addressed by a separate instrument (where and when necessary), second-best fuel taxes both in the US and the UK would be lower than they currently are. Sansom et al. (2001) find that UK charges per vehicle-kilometer are below marginal social costs. While this result differs from the Parry and Small (2005) study, both studies find that the congestion component dominates the marginal cost. Excluding congestion would bring UK charges roughly in line with marginal costs (Sansom et al., 2001, Table B). Climate change is much less important, given the assumptions on marginal damages. 


\section{Maritime transport ${ }^{10}$}

\section{Estimating greenhouse gas emissions from maritime transport}

We indicated in Section 3.2.1 that the emissions from shipping in the MoMo-model may be underestimated. This section details that claim and offers some observations on policy. In October 2008, the International Maritime Organization Marine Environment Protection Committee (MEPC) considered a study it commissioned to update its official estimate of fossil fuel use and $\mathrm{CO} 2$ emissions from international maritime activity. The study Greenhouse Gas Emissions from Ships: Phase 1 Report - federated all of the leading experts in bottom-up activity-based modelling of the world shipping fleet. They suggest a concensus estimate of $\mathrm{CO} 2$ emissions from international shipping of $843 \mathrm{Mt}$ in 2007 (see table below). This figure represents 45\% more than the study's estimated IEA 2007 CO2 emissions from marine bunkers and, for illustrative purposes, places 2007 international shipping emissions between the 2005 national emissions of India and Germany. The new estimate of $\mathrm{CO} 2$ from international shipping accounts for approximately $2.7 \%$ of world $\mathrm{CO} 2$ emissions from fossil fuel combustion with all shipping activity (fishing, domestic and international) representing approximately $3.3 \%$ of total $\mathrm{CO} 2$ from fuel combustion.

Table 3. Consensus estimate of 2007 CO2 emissions for Shipping (Mt CO2)

\begin{tabular}{|c|c|c|c|}
\hline & Low bound & Consensus & High bound \\
\hline Total Shipping Emissions & 854 & 1019 & 1224 \\
\hline Less fishing (activity-based) & $(58)$ & $(65)$ & $(74)$ \\
\hline $\begin{array}{l}\text { Total International and Domestic (activity- } \\
\text { based) }\end{array}$ & 796 & 954 & 1150 \\
\hline $\begin{array}{l}\text { Less IEA domestic shipping (Marine Bunker } \\
\text { fuel-based) }\end{array}$ & $(111)$ & $(111)$ & $(111)$ \\
\hline International Shipping (Hybrid estimate) & 685 & 843 & 1039 \\
\hline
\end{tabular}

Source: Buhaug, Ø. et al., 2008.

The recent IMO study (Buhaug et al., 2008) has sought to estimate future fuel use and CO2 emissions from shipping activity for 2020 and 2050 (see also Eyring et al., 2005). It uses a model based on 3 driving variables (economic activity, transport efficiency and embodied fuel energy) which, in turn, are related to a number of secondary variables e.g. population, regional economic growth, oil prices, technical efficiency improvements, etc.). Macro-economic, energy use and demographic variables are drawn from the IPCC SRES family of scenarios and extrapolations of historic trends are adjusted according to specific factors that are likely to have an impact on maritime transport demand (expressed as

10 This section deals with emissions only. Other environmental impacts are discussed briefly in Corbett and Winebrake, 2008. 
tonne/miles). These factors include adding new and expanding existing pipelines, upgrading the Transsiberian railroad, opening of the Arctic searoute, and increased recycling of iron.

These adjustements reduce maritime transport demand projections by up to half of what might otherwise been expected by extrapolating past GDP-maritime transport activity trends. Note that other factors, such as higher energy prices and changing production patterns, could change the relation between GDP growth and maritime transport growth.

According to Buhaug et al. (2008)'s central estimates for indexed future activity (indexed to 2007 tonne-miles), overall tonne-miles will grow by $30-46 \%$ by 2020 and by $150-300 \%$ by 2050. Container activity is projected to grow by much more: $65-95 \%$ by 2020 and $425-800 \%$ by 2050 . This growth, if realized, has important implications for fuel use and CO2 emissions since container vessels have more powerful engines and operate at higher speeds than most other vessels.

The IMO projections assume increases in fuel efficiency stemming from changes in average ship size (where this makes commercial sense -- larger ships being more fuel efficient at constant load factors than smaller vessels), changes in speed (estimated vessel fuel consumption has been modelled based on a third power relationship between speed and engine power output) and technical improvements to new vessels. The IMO baseline projections assumes no changes in the regulation of $\mathrm{CO} 2$ emissions or fuel consumption and so changes in efficiency (due to vessel design or operation) are assumed to track those improvements that are cost-effective under prevailing oil prices and commercial imperatives.

The IMO study also assesses the potential emission reductions from technological improvements. The bottom line is that, despite significant energy efficiency improvements (albeit slowly diffused through the fleet) $\mathrm{CO} 2$ emissions from international shipping would grow by $10-26 \%$ by 2020 and $126-218 \%$ by 2050 under baseline assumptions. Realising maximum potential efficiency improvements coupled with significant speed reductions and more intensive use of low-carbon fuels can lead to stabilized or slightly decreasing $\mathrm{CO} 2$ emissions from international shipping (low estimates) but these developments are unlikely to occur without significant changes and interventions.

The economic analysis of abatement strategies in shipping is hampered by the paucity of information on abatement costs, but some observations can be made. First, if abatement costs for $\mathrm{CO} 2$ follow patterns similar to those for NOx and SOx, then abatement costs in shipping are lower than in other transport modes. Second, changes in operational strategies - mainly reducing speed - provide the easiest short run options for abatement. Reducing speed is costly as it slows down the supply chain, but such costs may be limited as reliability may be as important as speed. Furthermore, the opportunity costs of holding inventories, which are inversely related to speed, decline as overall economic conditions are less favorable (slow steaming is one response to overcapacity). In the longer run, dispersion of technological innovation through fleet turnover can reduce emissions. However, turnover is slow and there is a large potential for leakage (moving less efficient vessels to regions where regulation is weaker or absent) as long as regulation is geographically restricted. Similar problems characterize abatement options in aviation. Third, while one might expect fuel economy choices in shipping to be optimal from at least a profit-maximizing point of view, the fact that the incidence of the fuel cost depends strongly on the particulars of shipping 
contracts $^{11}$ creates principal-agent problems that distort fuel economy choices. This problem is less prevalent in container shipping markets, however.

The outlook for multilateral action on handling shipping emissions is not simple (Kageson, 2009). The IMO faces difficulties in moving forward, as countries not bound by Annex 1 of the Kyoto Protocol favor action from those countries that are, while the latter favor broader multilateral initiative. If progress from the IMO side is unsatisfactory, the European Union may choose to move unilaterally, possibly with a regional trading scheme or inclusion of shipping into the ETS, in addition to emission-dependent harbor dues and binding CO2index limits. However, such trading schemes are prone to evasion by rerouting cargo through transshipment hubs.

\section{Other emissions}

Apart from generating greenhouse gases, emissions from maritime transport contribute to local air pollution in port communities as well as to regional air pollution. Marine bunker fuel is a residual fuel, relatively rich in contaminants, and no post-combustion treatment is required. One consequence is that the sulfur emissions per ton-mile are higher for ships than for other modes (Wang and Corbett, 2007). Requiring the use of higher quality fuels will reduce emissions per unit of fuel burned, and the International Maritime Organisation regulates the sulphur content of fuels. It sets global caps for SOx that become more stringent over time, and allows for Sulphur Emission Control Areas (SECAs) where stricter standards apply (including the Baltic Sea and the North Sea, and likely other areas in high income regions in the future ${ }^{12}$ ). Since 2005 , the global cap is $4.5 \%$ mass/mass sulfur content, whereas in SECAs the maximum is $1.5 \%$. The world average sulfur content of fuel was $2.7 \%$ in 2004. Wang and Corbett (2007) suggest that the benefits of turning the US West Coast into a SECA exceed the costs by a factor of about two, and that reducing sulfur content further to $0.5 \%$ increases the factor to about 3 (the exact result depending on the size of the SECA).

NOx is regulated in IMO through the NOx Technical Code with certification requirements for existing engines and standard test cycles to be applied to engines installed after 2011. Particulate matter, particularly black carbon, is recognized to be an important pollutant and GHG compound, but it is not regulated separately at this point - though fuel switching and improved engine performance of low-NOx engines should reduce particulate emissions.

The contribution of shipping to local air pollution is large in some areas. International trade routes are generally not far from land and pollutants travel over large distances. The costs of reducing emissions from shipping may be relatively low, given a longer history of regulation for other sources. For example, for the proposed USA-Canada SECA, compliance costs are expected to be no larger than those of further abatement from land sources. Abatement costs in shipping are estimated at USD 2600/ton of NOx, USD 1200/ton of SOx, and USD 11000/ton of PM. For comparison, the costs for highway diesel trucks are USD 2700/ton of NOx and USD 17000/ton of PM. The cost estimates include the increased

\footnotetext{
11 In different contexts vessel owners, cargo owners, or shippers may foot the fuel bill.

12 In March 2009, the Maritime Environment Protection Committee of the USA and Canada proposed the introduction of an Emission Control Area for NOx, SOx, and Particulate Matter (MEPC 59/5/X, 27 March 2009). This area would comprise of the main coastal zones of the USA and Canada.
} 
refinery costs as well as the costs of engine control, catalysts, reductants for NOx, and additional tankage costs. Compliance costs are not expected to affect demand in an appreciable manner, as there are few substitutes for maritime transport and the costs will increase the price of a new vessel by no more than $2 \%$ and operating costs no more than $3 \%$. The price of shipping a container could rise by about 3\% (USD 18).

\section{Aviation}

\section{Climate change}

Similar to maritime transport, the share of aviation emissions in total carbon emissions is small, but it is generally expected to grow fast. According to the business-as-usual scenario in Figure 1, emissions from aviation are set to grow faster than those of any other mode. While shares in emissions say nothing about abatement costs, it is often taken for granted that aviation should contribute to abatement.

A wide range of abatement measures can be thought of: charges (such as the UK air passenger duty of the Dutch ticket $\operatorname{tax}^{13}$ ), travel restrictions, emission standards, air traffic control reform, airport regulations or charges, limits on airport expansion, use of alternative fuels ${ }^{14}$, fuel or carbon taxes, and inclusion of aviation in emission trading schemes. The usual pro's and con's can be listed for these various measures. Some measures, e.g. the large scale adoption of biofuels, can be seen as voluntary industry measures or as responses to the introduction of carbon charges, and charges and standards may more usefully be regarded as complements than as substitutes.. The inclusion of aviation in trading schemes is proposed or decided on in several regions: the European Union has decided to include domestic flights and all aviation to or from the EU in the ETS, and Australia and New Zealand will include domestic aviation in their carbon trading schemes.

While trading schemes help equalize marginal abatement costs across the included sectors, and hence work towards reducing overall abatement costs, the trading schemes are not comprehensive and this leads to some shortcomings. For example, partial trading schemes involve a problem of leakage: passengers may choose to travel to destinations where carbon is cheaper, and airlines have incentives to use less energy-efficient aircraft outside of the trading zones. As long as charges are on a segment basis instead of an origindestination basis, airlines may also change their network structure, e.g. by making more intensive use of hubs near to trading zones so as to make flight segments within trading zones shorter. Airlines that dominate such hubs are in a better position to make such changes, so they may see their competitive position improve under a trading scheme. It is worth noting that policies to internalize external costs can be expected to affect competitive interactions in general, to the extent that different firms have different options in responding to changes in costs and regulations. The question hence is whether imperfect policies have excessively strong effects, that could be avoided by better policy.

13 Although it is not clear that these measures were primarily intended to curb greenhouse gas emissions.

See http://www.icao.int/WAAF2009/Documentation.htm for background on the potential of alternative fuels. 
According to Forsyth (2008), the scope for abatement through better fuel efficiency is limited, at least at the level of the industry. Fleet renewal tends to reduce emissions per passenger-kilometre with about $1 \%$ per year, but the possibilities of speeding up this process are limited. Putting a price on carbon hence will primarily affect airlines' variable costs. To the extent higher costs lead to higher fares, flight volumes will be affected. However, by many accounts, these effects are not negligible, but not very large either. Forsyth (2008) expects that, with a carbon price of $€ 20 /$ tonCO2, fares will increase by 2 to $6 \%$ if carbon costs are fully passed through to passengers. Schröder (2008) expects a cost increase for airlines of $2.5-5 \%$, and a demand reduction of $2.1-4.6 \%$, for an ETS where $15 \%$ of permits are auctioned and the cap equals $95-97 \%$ of the average emissions of $1995-1997$. In a report for the UK Commission for Integrated Transport, Wit et al. (2003) estimated the increase in short haul fares by around 3,5\% and long-haul fares by about $6 \%$. By taking an overall fare elasticity of demand of -0.8 , the DETR arrives at a reduction of demand for short-haul and long-haul travel by around 3\% and 5\% respectively. A CE Delft report (CE Delft, 2002) calculated the impact of the introduction of an emissions charge to be levied in European airspace, finding that a charge level of 50 Euros per ton $\mathrm{CO}_{2}$ might decrease air transport volume by roughly $2 \%$ for EU carriers. Anger et al. (2008) use a macroeconomic model to estimate the impact of including aviation in the EU ETS, and find limited effects: aviation is a net buyer of permits, requiring about $2.5 \%$ of the total supply of permits; at a permit price of $40 €$, demand for airline services is estimated to be $1 \%$ lower than the baseline in 2020 , while emissions drop by $7.5 \%$. The authors point out that if permits are auctioned, the revenues should not be recycled to non-ETS sectors, as this potentially undoes carbon savings.

Many studies assume that increased carbon costs are entirely reflected in higher fares, i.e. pass-through is complete. However, the extent of pass-through of cost increases to fares depends on the structure of the market. Under a Cournot structure - which is assumed to be appropriate for some air travel markets - pass-through is limited as long as no firms exit the industry, but fares can rise by more than carbon costs if there is exit. When permits are distributed for free, exit is discouraged, and this limits the impact of the carbon pricing scheme on abatement (Forsyth, 2008). The impact of carbon prices also depends on the (real or artificial) scarcity of airport capacity. When capacity is scarce, the introduction of carbon permits may do little more than reduce the opportunity cost of capacity (i.e. it may reduce the value of slots), while fares are hardly affected. Irrespective of the social value of such a transfer, the impact of the carbon price on greenhouse gas emissions will be limited.

\section{Aviation noise}

The damage caused by aviation noise is considerable. Noise damage is concentrated around airports, and it varies strongly among airports depending on the size of the population exposed, and among aircraft types. Lu and Morrell (2006) find that average noise costs per landing range from $16 €$ in Stansted to $774 €$ in Heathrow, with Schiphol holding the middle at $377 €$. For comparison, according to the same source, the costs of emissions per landing (including many local pollutants and CO2) are estimated at 626€, 1004€, and $842 €$ for the same three airports.

Noise pollution has been on the agenda for much longer than climate change, and a wide variety of measures is in place. Noise reduction at the source, as reflected in certification noise levels, has reduced perceived noise levels by about $1 / 3$ over 30 years (Girvin, 2009). Aircraft manufacturers design new aircraft taking noise-related policies into account. The fact that new aircraft do better than FAA and ICAO limits suggests that manufacturers design to the strictest standards in the market (often European airports). 
Airport noise levels can be reduced through land use measures, defensive expenditures, rules for operational procedures, and restrictions on operations. Some of these measures directly, and considerably, affect an airport's capacity. All these measures are used to varying degrees. Girvin (2009) observes that EU airports are more autonomous in this respect than those in the US, as in the latter airports are limited to restrictions on operations and operational procedures.

Policies have been effective. For example, while US air traffic increased by a factor of 3.5 between 1975 and 2000, exposure to significant noise declined by a factor of 16 . But expectations of continued traffic growth and increased resistance to noise (from a higher income population and well-organized interest groups) call for further action, while abatement costs increase. As in other areas of environmental policy, it then becomes increasingly important to try to keep the costs of further abatement down, and this increases the attractiveness of incentive-based measures, such as noise charges. Noise charges are in place in some airports, and are calculated on the basis of a variety of formulas and aircraft categories. However, many airports rely on command-and-control measures, which are unlikely to minimize costs. In this context, Niemeier (2008) shows evidence that noise constraints determine (peak) capacity at several large airports. "Government failure" of using inadequate noise reduction policies hence not only inflates the costs of attaining some target level of aviation noise, it also exacerbates the costs of inefficient use of scarce capacity. More widespread adoption of noise charges could reduce the costs of noise abatement. Given the strong dependence of impacts on local conditions, charges should not be harmonized, but harmonization of the mechanisms to calculate them may be desirable.

\section{Concluding remarks}

The picture on climate change management in transport that emerges from the preceding sections is twofold. Modes for which pre-existing policies are weak, such as shipping and aviation, seem to be candidates for integration into broader efforts to introduce climate change policy frameworks. Surface transport is characterized by stronger existing policies, and its integration in such broader frameworks is less straightforward.

The shape of the broader climate change policy frameworks is uncertain. Much of the economic analysis is on top-down approaches, and studies how multilateral efforts can handle the sovereignty constraint as well as possible. Policy developments, however, look more like a bottom-up approach, where different jurisdictions introduce more or less broad policies. This tendency should not be too surprising given the importance of club benefits in making effective climate change policy possible. While the bottom-up approach conceivably leads to gradual expansion of geographical coverage (e.g. by linking up US and EU carbon trading systems), the inclusion of developing economies like China and India remains problematic.

Inclusion of aviation and maritime transport in cap-and-trade systems that cover other sectors is desirable from a cost-effectiveness point of view. Both for aviation and maritime transport, technological abatement options are limited in the short run because of slow fleet turnover. In maritime transport, the impression is that operational measures can reduce CO2emissions to some extent in the short run, at relatively low cost. In aviation, there is some scope for abatement through better air traffic control and airport congestion management (as 
well as technology in the longer run), but the main intra-sector abatement is likely to come from lower demand. Available estimates put an upper bound of about $5 \%$ on demand reductions, at prices of around $€ 20 /$ tonCO2. Imperfect competition and airport congestion limit the extent of pass-through, and hence limit the demand responses. The aviation sector hence is likely to be a net buyer of permits. Both in aviation and shipping, there is considerable scope for leakage as long as trading schemes are not very comprehensive. Nevertheless, inclusion of these modes in trading schemes is desirable if overall abatement is to be cost-effective. Other incentive-based measures can yield similar benefits, but seem less acceptable. Broadening the geographical scope of trading systems for maritime transport and aviation is likely to be a gradual process, perhaps along the lines discussed in Kageson (2009).

Road transport is characterized by relatively stringent pre-existing policies. The EU has high fuel taxes and may introduce fuel economy standards. The US has low fuel taxes, and fuel economy is determined by the fuel economy standard. In the EU, road transport is not included in the ETS. In various US proposals, the idea is to include the sector, possibly through upstream trading between refiners. Since the pre-existing policies are relatively stringent, abatement costs for $\mathrm{CO} 2$ in road transport are relatively high, and exceed current and expected prices for carbon permits. This seems undesirable from a narrow costeffectiveness point of view, but since the prevailing policies serve other purposes than just greenhouse gas reductions, it is not immediately clear if the welfare cost of further tightening of these policies is very high. For example, higher fuel taxes in the US seem justified if the goal is to handle congestion (in a blunt way) and increase infrastructure cost coverage, and this policy would reduce greenhouse gas emissions. It deserves emphasis, however, that the policy justification is congestion management and infrastructure provision, not reducing greenhouse gas emissions.

Within the static welfare economic framework used above, the case for tighter fuel economy standards or higher fuel taxes in road transport to reduce greenhouse gas emissions is weak,. It is often argued, however, that policies are needed to increase the deployment of more fuel-efficient vehicles through the fleet. The reason is that the market for fuel economy provides only weak incentives to improve fuel economy, given consumers (rational) response to various uncertainties surrounding the investment in fuel economy. Given the additional market failures in research, development and diffusion of new technologies, a fuel economy standard seems to be a good instrument to increase fleet fuel economy and the adoption of alternative technologies. And since using less carbon to produce prevailing mobility patterns is likely to be a cheaper way to reduce the risks of climate change than drastically changing the structure of transport activity, such standards are an important part of a policy package, as a complement to market-based instruments in surface transport, aviation, and shipping. 


\section{References}

Abrell Jan, 2007, Transportation and emission trading - a CGE analysis for the EU 15, Economics of Global Warming Working Paper WP-EGW-01, Dresden University of Technology.

Aldy, Joseph E., 2006, Evaluating the costs and benefits of energy and climate change policies: an overview, presentation at a Symposium on Global energy and climate change, UCLA Extension Public Policy Program, Lake Arrowhead, California, October 2006.

Aldy, Joseph E., Eduardo Ley, and Ian W.H. Parry, 2008, A tax-based approach to slowing global climate change, Resources for the Future Discussion Paper 08-26.

An, Feng and Sauer, Amanda (2004). Comparison of Passenger Vehicle Fuel Economy and Greenhouse Gas Emission Standards around the World, Pew Center on Global Climate Change. http://www.pewclimate.org/global-warming-indepth/all reports/fuel economy/index.cfm.

Anger, Annela, Peter Allen, Jonathan Rubin, and Jonathan Köhler, 2008, Air transport in the European Union Emissions Trading Scheme, Final Report for Omega http://www.omega.mmu.ac.uk/Events/OmegaStudy 17 finalreport AAPMA 2-1 240209.pdfBarrett, Scott, 2005, Environment and Statecraft - The strategy of environmental treatymaking, Oxford University Press.

Barrett, Scott, 2007, Proposal for a new climate change treaty system, Economists' Voice, October 2007 (www.bepress.com/ev)

Buhaug, Ø., Corbett, J. J., Endresen, Ø., Eyring, V., Faber, J., Hanayama, S., Lee, D.S., Lee, D., Lindstad, H., Mjelde, A., Pålsson, C., Wanquing, W., Winebrake, J. J., and Yoshida, K., 2008, Updated Study on Greenhouse Gas Emissions from Ships: Phase I Report, International Maritime Organization (IMO) London, UK, 1 September 2008.

CE Delft, 2002, Economic incentives to mitigate greenhouse gas emissions from air transport in Europe, Report to DG TREN of the European Commission.

Corbett, James and James Winebrake, 2008, The impacts of globalization on international maritime transport activity - past trends and future perspectives, paper prepared for the Global Forum on Transport and Environment in a Globalizing World, Guadalajara, Mexico, November 2008.

Ellerman, Denny A., Henry D. Jacoby, and Martin B. Zimmerman, 2006, Bringing transportation into a cap-and-trade regime, MIT Joint Program on the Science and Policy of Global Change, Report No. 136.

Ellerman, Denny A., 2008, The EU emission trading scheme: a prototype global system?, Harvard Kennedy School, Harvard Project on International Climate Agreements, Discussion Paper 08-02. 
European Union (EU), 2007, Commission Staff Working Document - Accompanying document to the Proposal from the Commission to the European Parliament and Council for a regulation to reduce $\mathrm{CO}_{2}$ emissions from passenger cars - Impact Assessment, SEC(2007) 1724.

Eyring V., H. Köhler, A. Lauer, and B. Lemper, 2005, Emissions from international shipping 2: impact of future technologies on scenarios until 2050, Journal of Geophysical Research, 110.

Forsyth, Peter, 2008, The impact of climate change policy on competition in the air transportation industry, JTRC Discussion Paper 2008-18.

Girvin, Raquel, 2008, Aircraft noise abatement and mitigation strategies, Journal of Air Transport Management, 15, 14-22.

Glazer, Amihai and Charles Lave, 1996, Regulation by prices and by command, Journal of Regulatory Economics, 9, 191-197.

Greene David L., John German and Mark A. Delucchi, 2008, Fuel economy: the case for market failure, Chapter 11 in Dan Sperling and James Cannon (eds.), forthcoming.

Harrington, Winston and Virginia McConnell, 2003, Motor Vehicles and the Environment, Resources for the Future Report (April), http://www.rff.org/rff/Documents/RFF-RPTcarsenviron.pdf.

JTRC, 2008a, The cost and effectiveness of policies to reduce vehicle emissions, JTRC Discussion Paper 2008-9, ITF/OECD, Paris.

JTRC, 2008b, Transport Outlook 2008: Focusing on CO2 Emissions from Road Vehicles, JTRC Discussion Paper No 2008-13, ITF/OECD, Paris.

Kageson, Per, 2009, Making international transport pay its climate bill, paper prepared for the Workshop on Environmental impacts of international transport, International Transport Forum, Leipzig, May 2009.

Leiby, Paul N., 2007, Estimating the Energy Security Benefits of Reduced U.S. Oil Imports, Report No. ORNL/TM-2007/028, Oak Ridge National Laboratory, Oak Ridge, Tennessee, February.

Lu, Cherie and Peter Morrell, 2006, Determination and applications of environmental costs at different sized airports - aircraft noise and engine emissions, Transportation, 33, 45-61.

Maritime Environment Protection Committee, 2009, Consideration and Adoption of Amendments to Mandatory Instruments - Proposal to designate and emission control area for Nitrogen Oxides, Sulfur Oxides and Particulate Matter submitted by the United States and Canada, MEPC 59-5/x, 27 March 2009.

Meckling, Jonas, 2008, Corporate policy preferences in the EU and the US - Emissions trading as the climate compromise?, Carbon and Climate Law Review, 2, 171-180. 
Newell, Richard, 2008, Inducing innovation for climate change mitigation, Resources for the Future Weekly Policy Commentary, February 112008.

Niemeier, Hans-Martin, 2008, Airports and the Environment. How to balance economic and environmental concerns, presentation at the "Aviation and the Environment" GARS Workshop at the International University of Applied Sciences,Bad Honnef 26th and 27th November 2008 - http://www.garsonline.de/

Nordhaus, William D., 2007, To tax or not to tax: alternative approaches to slowing global warming, Review of Environmental Economics and Policy, 1, 1, $26-44$.

Parry, Ian W.H., 2007, Are the Costs of Reducing Greenhouse Gases from Passenger Vehicles Negative?, Journal of Urban Economics, 62, 2, 273-293.

Parry, Ian W.H. and Kenneth A. Small, 2005, Does Britain or the United States have the right gasoline tax?, American Economic Review, 95, 1276 - 1289.

Proost S., 2008, Full Account of the Costs and Benefits of Reducing CO2 Emissions in Transport, JTRC Discussion Paper No 2008-3, ITF/OECD, Paris.

Sansom, Tom, Chris Nash, Peter Mackie, Jeremy Shires, and Paul Watkiss, 2001, Surface transport costs and charges - Great Britain 1998, ITS Leeds in association with AEA Technology Environment.

Schröder, Andreas, 2008, Incorporating aviation into the EU emissions trading system, presentation at the GARS conference on aviation and climate change, Amsterdam, July 2008.

Small K. and K. Van Dender, 2007, Long run trends in transport demand, fuel price elasticities and implications of the oil outlook for transport policy, JTRC Working Paper 07-16, ITF/OECD, Paris.

Stern, Nicholas, 2006, The Economics of Climate Change: The Stern Review, HM Treasury, London.

http://www.hm-

treasury.gov.uk/independent reviews/stern review economics climate change/stern review $r$ eport.cfm

Stiglitz, Joseph E., 2006, A new agenda for global warming, Economists' Voice, July 2006 (www.bepress.com/ev)

Tol, Richard S.J., 2005, The marginal damage costs of carbon dioxide emissions: an assessment of the uncertainties, Energy Policy, 33: 2064-2074.

Turrentine, Thomas and Kenneth Kurani, 2007, Car buyers and fuel economy? Energy Policy, 35, 1213-1223.

Van Dender, Kurt, 2008, Energy policy in transport and transport policy, Energy Policy, forthcoming. 
Wang C. And James Corbett, 2007, The costs and benefits of reducing $\mathrm{SO}_{2}$ emissions from ships in the US West Coastal waters, Transportation Research D, 12, 577-588.

Weitzman, Martin L., 2007, A review of the Stern Review on the Economics of Climate Change, Journal of Economic Literature, 45: 703-724.

Weitzman, Martin L., 2008, On modelling and interpreting the economics of catastrophic climate change, mimeo.

Wit, Ron, Marc Davidson and Jos Dings, 2003, Meeting external costs in the aviation industry, CE Delft, Delft. 